OPEN ACCESS

Edited by:

Emily Chu,

National Institutes of Health (NIH),

United States

Reviewed by:

Bruno C. V. Gurgel,

Federal University of Rio Grande do

Norte, Brazi

Pia Lopez Lopez Jornet,

University of Murcia, Spain

*Correspondence:

Amit Acharya

amit.acharya@aah.org

Specialty section: This article was submitted to

Systems Integration,

a section of the journal

Frontiers in Dental Medicine

Received: 28 February 2021 Accepted: 28 September 2021 Published: 02 November 2021

Citation:

Shimpi N, Panny A, Glurich I,

Chyou P-H and Acharya A (2021)

Knowledgeability, Attitude and

Practice Behaviors of Dental Providers Toward Provisions of Integrated Care

Delivery for Patients With

Prediabetes/Diabetes: Wisconsin

Statewide Survey.

Front. Dent. Med. 2:674178. doi: $10.3389 /$ fdmed.2021.674178

\section{Knowledgeability, Attitude and Practice Behaviors of Dental Providers Toward Provisions of Integrated Care Delivery for Patients With Prediabetes/Diabetes: Wisconsin Statewide Survey}

\author{
Neel Shimpi ${ }^{1}$, Aloksagar Panny ${ }^{1}$, Ingrid Glurich ${ }^{1}$, Po-Huang Chyou ${ }^{1}$ and Amit Acharya ${ }^{2 *}$ \\ ${ }^{1}$ Center for Oral and Systemic Health, Marshfield Clinic Research Institute, Marshfield, WI, United States, ${ }^{2}$ Center for Oral \\ and Systemic Health, Aurora Research Institute, Milwaukee, WI, United States
}

Introduction: To conduct a statewide survey among Wisconsin-based dental providers evaluating current knowledgeability, attitudes and practice behaviors surrounding management of patients with diabetes/prediabetes in the dental setting. The study explored perceptions on feasibility, value, barriers, and current status of integrated care model (ICM) adoption by dental practices

Materials and Methods: A 32-question paper-based survey was mailed to all licensed dentists and dental hygienists practicing in Wisconsin. The study was conducted over a 4 week period in 2019. The survey instrument was adapted from a previous validated survey and was expanded to include questions on ICM adoption. Content and validity analyses and beta testing were conducted prior to dissemination of the survey. Descriptive statistics and chi-square tests were applied for data analyses. Thematic analyses was performed on open-ended questions.

Results: Survey response rate was $12 \%(N=854 / 7,356)$ representing $41 \%$ dentists and $59 \%$ dental hygienists. While $68 \%$ reported educating patients on oral health-diabetes association, only $18 \%$ reported medical consultations to inform dental treatment, and "frequent" (22\%) or "occasional" (40\%), medical triage. Knowledge-based questions were correctly answered by $>70 \%$ of participants. While $50 \%$ valued chair-side glycemic screening and $85 \%$ supported non-invasive chair-side screening to identify at-risk patients, $>88 \%$ relied on patient-reported diabetic status. Barriers to ICM adoption included time investment (70\%), patient activation/cooperation (62\%), cost (50\%), insurance coverage (50\%), infrequent interdisciplinary communication (46\%), lack of equipment (33\%) and provider (31\%).

Conclusion: Low rates of ICM adoption, chair-side testing, medical consultation and triage, and need for educational curricula reform were identified.

Keywords: attitudes, health care surveys, health knowledge, interprofessional relations, oral health, patient care team, practice statewide dental providers survey for integrated care models 


\section{INTRODUCTION}

A mounting evidence-base supports the bi-directional association of periodontal disease and type 2 diabetes mellitus (T2DM) (1-4). Evidence-based support of oral and systemic health association promotes a need to reform the traditional practice paradigm through incorporation of integrated care delivery models for the currently silo-ed medical and oral health care delivery system. Several studies have reported that patients withT2DM, receiving regular and timely oral healthcare have shown an overall decrease in healthcare expenditure and hospital admission rates (5-10). Dental providers can screen for a spectrum of medical conditions that simultaneously exhibit oral manifestations and are thus ideally positioned to identify at-risk individuals during the preventive and therapeutic dental appointments $(11,12)$. For example, oral manifestations of T2DM include periodontitis, salivary dysfunction, tooth decay, and oral ulcers, among others. Presence of these conditions herald underlying systemic physiological imbalances where dental providers are centrally positioned to play a key role in assessing the patient risk and proactively triaging patients with appropriate referrals in a timely manner (13). Moreover, because of the variability in the underlying etiology giving rise to distinct forms of diabetes, establishment of true diagnosis is important to determination of appropriate dental and medical management by the dental and medical providers, respectively. Such approaches promote earlier recognition, potential prevention and early intervention especially in the context of interactive oral systemic chronic conditions, with the added benefit of improving and managing patient health at reduced cost.

The United States Surgeon General Report of 2000 (14) highlighted the overall need for oral and systemic health integration and this has been reiterated in Healthy People 2020 (15). Establishing a common platform for collaborative approaches will promote increased quality of care and inform alternative models of care that promote improved patient outcomes through implementation of cost-effective strategies. Studies have demonstrated the willingness of both medical and dental providers in provision of screenings across specialties to help improve health outcomes and reduce financial burdens for individuals and society as a whole (16-18). However, creating a common platform depends on various factors, including knowledgeability of oral and systemic association, interdisciplinary health education training and geographic proximity of medical and dental healthcare, among others $(11,13,17,19)$. Additionally paradigm redesign will require collaboration across a spectrum of stakeholders to achieve the transformation.

In the state of Wisconsin, approximately $11.2 \%$ of the adult population has been diagnosed with T2DM, while nearly $26 \%$ remains undiagnosed (20). A 2016 report by the American Diabetes Association (ADA) estimated that the state incurred nearly $\$ 5.9$ billion in direct costs in the context of providing care and indirect costs due to missed workdays or productivity losses for individuals with diagnosed and undiagnosed diabetes (20). T2DM is targeted by Wisconsin's chronic disease prevention program which provides a coordinated approach to identifying risk factors and comorbid complications of diabetes, and builds strategies to address these $(21,22)$. The aim of the current study was to evaluate the current knowledgeability, attitudes and practice behaviors among dental providers in order to better understand current management strategies of patients with diabetes/prediabetes. This study updates and expands on a previously published study (16), through inclusion of additional domains that explore current status and barriers for establishing integrated care delivery in the context of diabetes or prediabetes and other underlying systemic conditions that potentially may synergize and impact oral health outcomes.

\section{DESIGN AND METHODS}

\section{Survey Tool}

An anonymous 32-question survey tool consisting of four sections including demographics, current practices, knowledgeability and opinions was developed (shown in Supplementary Material). The survey instrument was adapted from an existing validated survey and expanded to include additional questions on adoption of medical and dental integration (16). Study team members with appropriate expertise conducted content and validity analyses and beta testing prior to dissemination of the survey tool. The demographic section included a total of six demographic questions including age, gender, role, name of dental-related school, year of graduation, and total years of professional experience. Seven questions configured in a multiple-choice format was included in the knowledgeability section. These consisted of questions regarding oral manifestations/complications of diabetes (four questions, including a clinical scenario question) and biological glycemic evaluation (three questions). Current practice and Opinion sections used five-point Likert scale options to record opinions and responses regarding current practice-based questions. Likert scale categorization was formatted as follows: $1=$ very well trained/very frequently/very important/very willing, 2 = well trained/frequently/important/somewhat willing, 3 $=$ not sure/occasionally/moderately important, $4=$ limited training/rarely/ moderately important/Somewhat unwilling and $5=$ no training/never/Not important /very unwilling. The current practices questions $(n=13)$ assessed practice activities including patient education about diabetes and oral health; patient referral to medical providers and physician consultation prior to dental treatments; and practices regarding chair-side screening for diabetes, prediabetes, hypertension and obesity. The opinion sub-section consisted of six questions that captured provider opinions regarding various aspects of incorporating diabetic screening into their dental practice. The survey tool and study were reviewed and approved by the internal institutional review board of Marshfield Clinic Health Systems.

\section{Survey Dissemination}

All licensed dentists and dental hygienists practicing in state of Wisconsin were eligible to participate in the survey. A list of all the practicing dental providers was purchased from American Dental Association (ADA). Eligible participants were sent mails that included a letter of invitation that had a description of study 
and information regarding options to access, a hard copy of the survey and a return envelope with the paid postage. Participants were given options to complete the paper-based survey or online survey or a phone-based survey by calling a toll-free number. Participation was voluntary and anonymous. The survey was conducted over a 4 week window with analyses completed in September of 2019. To encourage participants to complete the survey, reminders were sent by another set of mailing to the participants at end of week 2 .

\section{Data Analysis}

At the end of survey period, the data was collected and entered into a REDCap database (23). A 10\% data validation was performed on the data entered by two authors [NS, AP]. Descriptive and statistical methods were used to analyze data and thematic analyses were conducted on open- ended questions. Rates of missing data were calculated for each question and reflected in the denominator. The survey responses were grouped into various categories to facilitate high-level analyses. Age was grouped into six categories: $(18-30 ; 31-40 ; 41-50$; 51-60; 61-70 and 71-80); years of graduation was grouped into six categories $(<1970$; 1971-1980; 1981-1990; 1991-2000; 20012010 ; > 2011) region was categorized into four categories (west, south, midwest, and northeast,) and years of experience were categorized into 5 groups $(<10 ; 11-20 ; 21-30 ; 31-40$ and $>40)$. Statistical significance was set at $p$-value $<0.05$. Chi-square tests were used to analyze data based on broad comparison groups including: role (Dentist vs. Dental Hygienist), year of graduation $(<1990$ vs. $>1991)$ and years of experience (<20 vs. $>21)$.

Likert scale responses were grouped into two sub-categories reflecting degree of positive or negative engagement. For instance responses to questions regarding the frequency of an activity (e.g., "very frequently," "frequently," "occasionally," "rarely," and "never") were grouped as frequently (for respondents who had selected "very frequently," "frequently), and infrequently (for respondents who selected "occasionally," "rarely," or "never").

Content analysis of open-ended responses for three questions was conducted by two co-authors [NS, AP] by grouping them into larger categories. The three open-ended queries were:(1) resources used for remaining updated on oral-systemic health; (2) factors contributing better management of at-risk/diabetic patients in dental setting, and (3) barriers for medical-dental integration. The researchers also defined additional themes in addition to the existing ones to categorize the responses. The inter-rater reliability was calculated using Cohen's kappa. Data analysis was performed using SAS 9.4 Version.

\section{RESULTS}

\section{Respondent Demographics}

A $12 \%(n=854 / 7,356)$ response rate was achieved among targeted providers who returned completed surveys. Of these, 782 completed paper-based surveys and 72 participants completed online surveys. Among participants, $41 \%$ were dentists and $59 \%$ were dental hygienists. The majority of participants (95\%) graduated from dental schools located in Midwestern region of the United States. Mean age and years of professional
TABLE 1 | Shows the summary of participant demographics with respect to role.

\begin{tabular}{|c|c|c|c|}
\hline & Dentist $N(\%)$ & Hygienist $\boldsymbol{N}(\%)$ & $p$-value \\
\hline Age & & & $<0.0001$ \\
\hline $18-30$ years & $34(9.9)$ & $36(7.2)$ & \\
\hline $31-40$ years & $65(18.8)$ & $63(12.7)$ & \\
\hline $41-50$ years & $50(14.5)$ & $132(26.5)$ & \\
\hline $51-60$ years & $101(29.2)$ & 197 (39.6) & \\
\hline $61-70$ years & $80(23.2)$ & $62(12.5)$ & \\
\hline $71-80$ years & $14(4.0)$ & $7(1.4)$ & \\
\hline$>80$ years & $1(0.1)$ & $1(0.2)$ & \\
\hline Gender & & & $<0.0001$ \\
\hline Female & $106(31.0)$ & $487(98.2)$ & \\
\hline Male & $236(69.0)$ & $9(1.8)$ & \\
\hline Years of professional experience & & & 0.013 \\
\hline$<10$ years & $83(24.6)$ & $79(16.6)$ & \\
\hline $11-20$ years & $54(16.0)$ & $102(21.5)$ & \\
\hline $21-30$ years & $72(21.4)$ & $125(26.3)$ & \\
\hline $31-40$ years & $101(30.0)$ & $141(29.7)$ & \\
\hline$>40$ years & $27(8.0)$ & $28(5.9)$ & \\
\hline Year of graduation & & & $<0.0001$ \\
\hline$<1970$ & $10(2.9)$ & $18(3.7)$ & \\
\hline $1971-1980$ & $65(19.1)$ & $76(15.4)$ & \\
\hline $1981-1990$ & $113(33.1)$ & $143(29.0)$ & \\
\hline $1991-2000$ & $49(14.4)$ & $144(29.2)$ & \\
\hline 2001-2010 & $48(14.1)$ & $83(16.8)$ & \\
\hline$>2010$ & $56(16.4)$ & $29(5.9)$ & \\
\hline Region of school graduated & & & 0.0012 \\
\hline Northeast & $10(3.0)$ & $2(0.4)$ & \\
\hline Midwest & $308(92)$ & $486(97.6)$ & \\
\hline South & $10(3.0)$ & $5(1.0)$ & \\
\hline West & $7(2.0)$ & $5(1.0)$ & \\
\hline
\end{tabular}

experience of respondents was $50.1 \pm 12$ (years) and $24.2 \pm 12.5$, respectively. Of the total participants, $70.8 \%$ were females. The majority of respondents (53.8\%) graduated between 1981 and 2000; while $20 \%$ graduated before 1981 and $25.9 \%$ graduated after 2000. Twenty-one respondents did not disclose the region of their dental-related school. Table 1 shows the summary of participant demographics with respect to role.

\section{Practice Behavior}

Sixty percent (210/344) of the dentists and 57\% (274/492) of the hygienists reported receiving training to address and manage patients with diabetes. Eighty percent (172/213) of the participants who graduated from a dental-related professional school after the year 2000 stated receiving some training to manage patients with diabetes compared to only $50 \%$ (303/607) who graduated in/before the year 2000. All the respondents reported access to multiple resources for attaining continuing education surrounding oral- systemic health topics including scientific journals (77.2\%;659/854); media/news (27.7\%; 237/854), continuing education programs (93.6\%; 800/854); magazines/books (49.3\%; 412/854); internet 
(6.3\%; 54/854); personal experience $(0.9 \% ; 8 / 854)$; patient feedback $(0.7 \% ; 6 / 854)$ and colleagues $(6 \% ; 53 / 801)$. Table 2 summarize the ratings assigned by the respondents regarding training received at their dental-related schools with respect to managing patients with diabetes with respect to role, years of graduation and years of professional experience.

A total of $67.5 \%$ (570/845) indicated that they educate patients surrounding prediabetes and diabetes often (very frequently + frequently); while the referral rate for at-risk/diabetic patients to a medical provider was only $22 \%(186 / 844)$ who indicated "frequently" and 39.6\% (334/844) indicating "occasionally". Approximately 18\% (149/842) of dentists and 35.8\% (301/842) dental hygienists indicated that they consult physicians for evaluation prior to a dental treatment. The majority of participants $(>88 \%)$ indicated that they physically never screen the patient and rely on patient- reported status for prediabetes or diabetes. Only about $11 \%$ of providers indicated that they access electronic health records (EHR) to determine patient status for prediabetes, diabetes and hypertension. The percentage indication by the respondents for contacting the patient's medical providers for the medical conditions was: $7.3 \%$-for prediabetes; $17.6 \%$-for diabetes; $16.7 \%$-for hypertension and $5.3 \%$-for obesity, respectively.

\section{Knowledgeability}

The correct response that torus palatinus or palatal tori is not a complication of diabetes was identified by $96.5 \%$ (804/845) of the participants. Approximately $89 \%$ of participants who were dentists and $90 \%$ of participants who were dental hygienists identified correctly the symptoms of untreated DM. The percentage of Hemoglobin A1C (HbA1C) in blood for prediabetes is between 5.7 and $6.4 \%$ was correctly answered by about $58 \%$ of the participants; while $61 \%$ correctly identified that blood glucose levels greater or equal to $>126 \mathrm{mg} / \mathrm{dl}$ indicated diabetes. Approximately $92 \%$ of participants correctly identified that "tooth abrasion" is not a sign of insulin resistance. The option: "Proceeding with an invasive dental procedures with instructions to discontinue hypertensive medications" was correctly selected by about $84 \%(406 / 485)$ of the hygienists and $88 \%(299 / 337)$ of the dentists in response to the question related to preoperative dental considerations for a patient with $\mathrm{HbA} 1 \mathrm{c}$ of $9.0 \%$ and a blood pressure of $150 / 90 \mathrm{~mm}$ of $\mathrm{Hg}$. That HbA1C test does not reflect day-to-day changes in glycemic levels, was correctly identified by about $64 \%$ of the participants.

\section{Opinions}

Approximately $86 \%(724 / 839)$ of the providers opined that it is "very important" or "important" for medical and dental providers to work together for better management of pre-diabetic/diabetic patients. Figure 1 shows the features indicated by the participants that would likely contribute to better management of atrisk/diabetic patients in dental settings. Approximately $26 \%$ of the providers indicated willingness to conduct chair-side biological glycemic measure screening; while $27 \%$ mentioned "somewhat willing", 22.4\% were "not sure" and 25\% were not willing. About $85 \%$ of the participants indicated that they were "very willing" or "somewhat willing" to incorporate noninvasive screening methods to identify at-risk patients and $95 \%$ of the participants were willing to refer at-risk patients to medical providers. The data collected from the responses to the opinions of participants regarding barriers representing strongest impediment to medical and dental integration were coded and identified into various themes by two coders. Cohen's kappa analysis determined inter-rater reliability to be 0.96 (96\%), indicating excellent agreement between the two coders. Figure 2 summarizes the opinions of participants regarding barriers representing the strongest impediments to medical and dental integration.

\section{DISCUSSION}

The present study evaluated dental provider practice behaviors, knowledgeability, attitudes and perceptions related of integrated care delivery in context of diabetes/prediabetes by employing survey methodology. Overall, positive attitudes among participants toward adoption of integrated medical-dental care delivery models were noted. Collectively, based on responses to knowledge-based questions, participants in this study indicated a high awareness (88-90\%) of association between oral health and diabetes. Other studies have reported variability in knowledge levels among dental providers. A cross sectional survey study conducted by Paquette et al., (24) of about 600 dentists in North Carolina reported that around 94\% of dentists identified diabetes as a risk factor for periodontitis. The percentage of dentists reporting knowledgeability of assessing DM risk was $47 \%$ in a survey conducted by Esmeli et al., (25). In the present study, approximately $42 \%$ dental hygienists reported to have lack of knowledge about $\mathrm{HbA1C}$ values. These rates were lower than those reported in a study conducted Boyd et al., (26) where $50 \%$ of participants $(n=392)$ lacked knowledge about HbA1c values. Notably, around $60 \%$ of the total participants in the present study reported some training on DM management in dental offices. The relationship between the variables "year of graduation from a dental-related professional school" vs. "amount of training received to address and manage patients with DM" was statistically significant $(p=<0.0001)$. These data suggest that there is a greater need for inter professional training of dental providers and an emphasis is required for increased medical-dental communication.

Although dental providers indicated receptivity to incorporating integrated care models in their practices, presently only about $12 \%$ of providers indicated that they physically screen patients for prediabetes or diabetes. Hypertension was the condition most commonly screened by dental hygienists and dentists compared to the other conditions. Rates of chair-side screening for hypertension in this study were comparable to rates reported by other studies $(16,27)$. This study found time constraints and lack of patient cooperation as the major barriers to adoption of integrated care models, followed by cost, insurance reimbursement and lack of communication between medical and dental providers. Studies conducted in various countries also showed that "lack of time" was a major barrier 


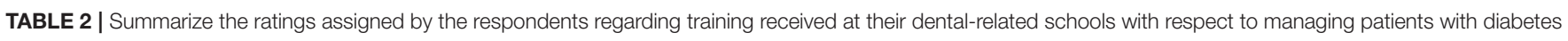
with respect to role, years of graduation and years of professional experience.

\begin{tabular}{|c|c|c|c|c|c|c|c|c|c|}
\hline \multirow[b]{2}{*}{ Likert Scale } & \multicolumn{3}{|c|}{ Role } & \multicolumn{3}{|c|}{ Year of graduation } & \multicolumn{3}{|c|}{ Years of professional experience } \\
\hline & Dentist $N(\%)$ & Hygienist $\boldsymbol{N}(\%)$ & $p$-value & $<1990 N(\%)$ & $>1990 N(\%)$ & $p$-value & $<20$ years & $>20$ years & $p$-value \\
\hline Excellent & $51(39.5 \%)$ & 78 (60.5\%) & 0.16 & 49 (38.6\%) & $78(61.4 \%)$ & $<0.0001$ & $63(50.4 \%)$ & $62(49.6 \%)$ & $<0.0001$ \\
\hline Well-trained & $159(44.8 \%)$ & $196(55.2 \%)$ & & 137 (39.4\%) & $211(60.6 \%)$ & & $171(50.6 \%)$ & $167(49.4 \%)$ & \\
\hline Neutral & $33(40.2 \%)$ & 49 (59.8\%) & & $54(67 \%)$ & $26(33 \%)$ & & $19(24.4 \%)$ & $59(75.6 \%)$ & \\
\hline Poor & 95 (39\%) & $148(61 \%)$ & & $158(66 \%)$ & $81(34 \%)$ & & 57 (24.5\%) & $176(75.5 \%)$ & \\
\hline Not at all & $6(22 \%)$ & $21(78 \%)$ & & $20(77 \%)$ & $6(23 \%)$ & & 4 (17.4\%) & 19 (82.6\%) & \\
\hline
\end{tabular}

Chi-square tests were used to analyze data based on comparison groups presented in this table.

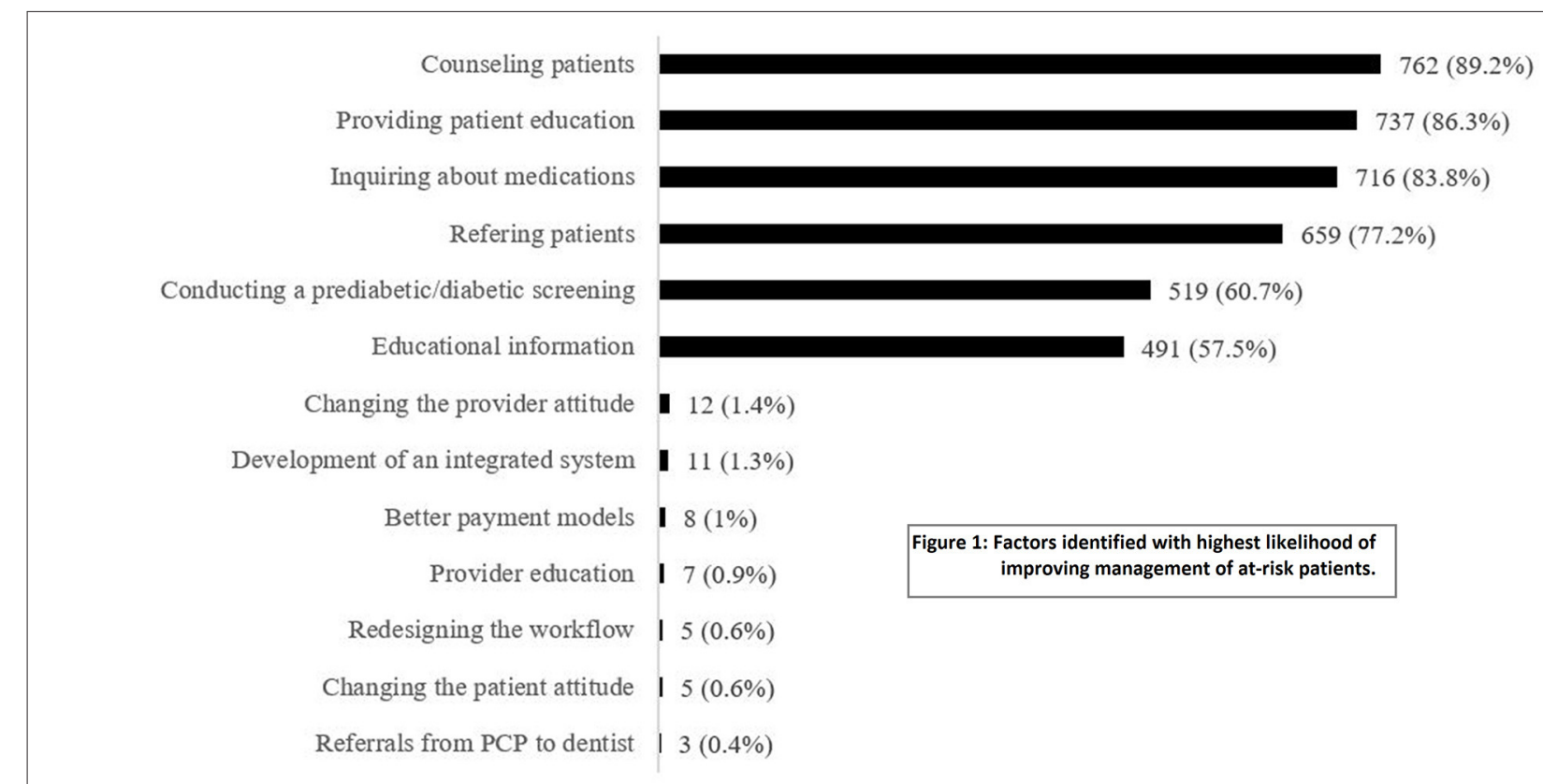

FIGURE 1 | Shows the features indicated by the participants that would likely contribute to better management of at-risk/diabetic patients in dental settings.

for screening patients for systemic disease (27-29). A similar study among medical providers in state of Wisconsin, also cited lack of insurance, lack of interdisciplinary communication and time constraints are major factors for barriers to medical-dental integration (30).

Rates at which dentists and hygienists referred patients to a medical provider differed from rates at which they reported educating patients about diabetes and oral health. Whereas, 23.6 and $20.8 \%$ of dentists and hygienists, respectively, reported frequently referring diabetic patients to medical providers, 62 and $70 \%$ of dentists and hygienists respectively, reporting frequently educating patients about diabetes and oral health. Although, this study identified lack of frequent consultations/referrals to medical providers, the majority (95\%) of participants were willing to refer their patients to medical providers. These finding suggest the need for implementation of referral mechanisms within the electronic health records which would facilitate and promote referrals to medical providers.
Study results showed willingness to incorporate chair-side medical screenings that may establish alternative best practices that promote the concept of value-based care delivery. Previous studies have shown similar findings. For example, survey research conducted by Greenberg et al., (27) among 2,000 general dentists reported that around $77 \%$ of them felt it was important to conduct screening for diabetes in their clinic. Another crosssectional survey of 265 general dentists by Esmeili et al., (25) reported that around $61 \%$ of the dentists believed that addressing diabetes was important to their role as a dentist. By contrast, a study conducted by Kunzal et al., (31) in the north eastern US states found that the majority of general dentists believed that managing patients with diabetes in dental setting falls outside of their scope of practice and their patients and colleagues had no expectations from them to perform these activities. In this study, the majority of the participants (85\%), indicated that they were willing to incorporate approaches involving non-invasive screening methods for at-risk patients in their practice. Previous 


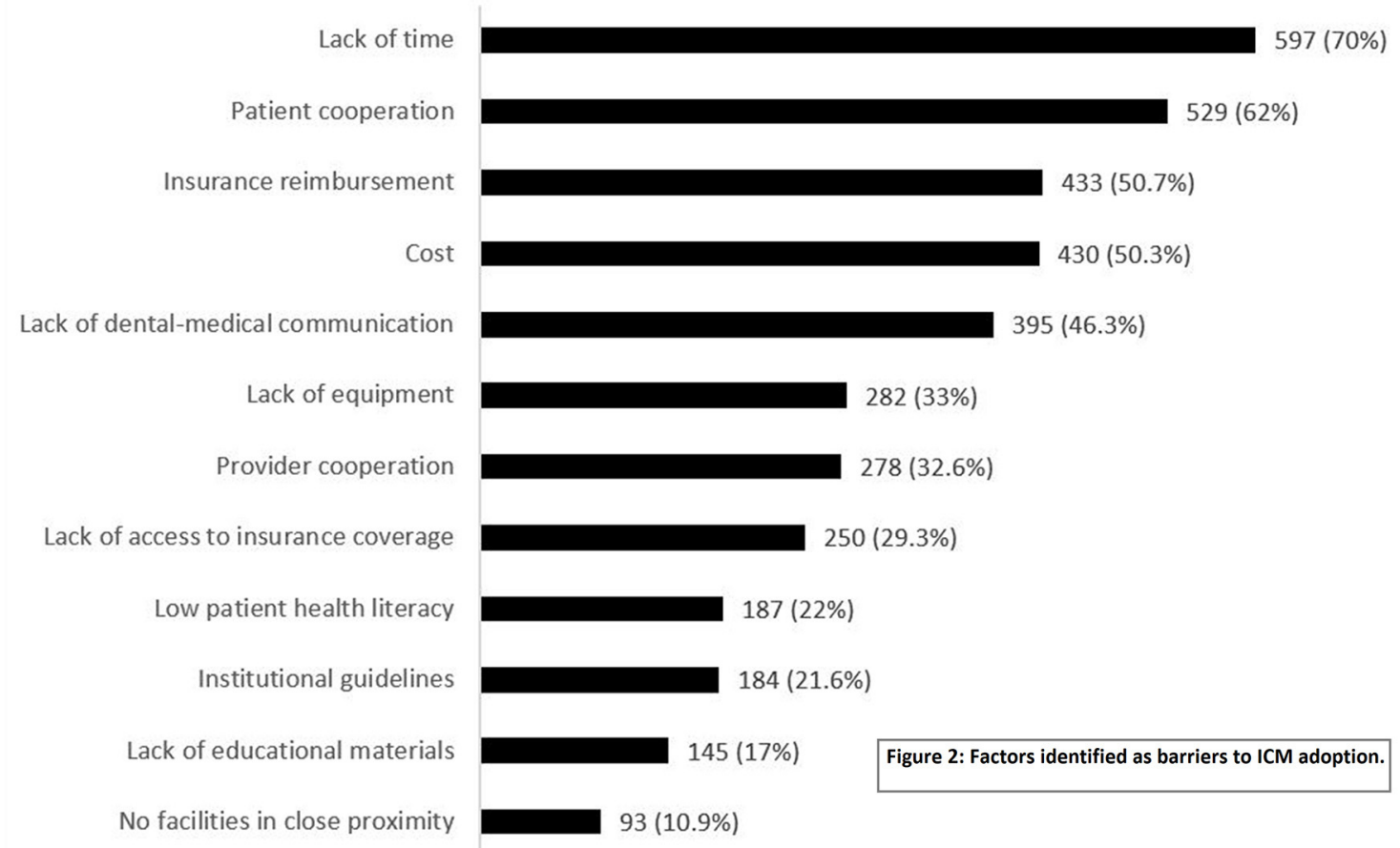

FIGURE 2 | Summarizes the opinions of participants regarding barriers representing the strongest impediments to medical and dental integration.

studies have developed prototypes of diabetes risk assessment tools that have shown that identifying at-risk patients in dental settings could be beneficial to patient health outcomes (32-36).

Studies continue to show there evidence of bi-directional association of diabetes and periodontal diseases, thereby justifying the importance of screening medical conditions and management of diabetes in dental settings. It was reported by the American Diabetes Association (ADA) in 2018 that 88 million people have prediabetes and 32.4 million had diabetes among whom 7.3 million remained undiagnosed (37). These data further support the expanded role for dental providers in promoting patient education surrounding oral-systemic association and referral of patients to medical practitioners in timely manner to avoid systemic complications. The new global classification of periodontal and peri-implant diseases has proposed to include evidence-based and clinically relevant system that focuses on improving the communication and effective treatment to patients. The classification also includes systemic diseases such as T2DM as a risk factor for periodontal and peri-implant diseases (38). The integration of oral and systemic health in dental and medical school curricula can be more effective in achieving holistic patient care $(39,40)$.

The study acknowledges some limitations. The study data provided by the participants was anonymous and self-reported and hence validation of the findings is limited. The study did collect the information on practice settings (i.e., individual/solopractices) and whether care delivery infrastructure was supported by integrated medical-dental practice. Whereas, a previous study also collected data on willingness to collect saliva samples in dental settings for blood glucose testing (27), our survey was limited to questions surrounding evaluation of blood glucose levels or use of non-invasive predictive approaches. Collection of such data may be of value in future studies to understand alternative approaches to identifying at-risk patients in dental settings.

Study findings provide valuable provider insights to inform the development of a national framework for medical-dental integration currently being collaboratively advanced by Centers for Disease Control and Prevention and National Association of Chronic Disease Directors and multidisciplinary stakeholders in 2021 (41), to effectively minimize current barriers to adoption of integrated care models also identified by the survey participants. Periodic resurveying the dental practitioner will be worthwhile to observe changes in receptivity to adoption of integrated care models into their practices.

A further study limitation is that the survey tool did not distinguish between various diabetes subtypes. Whereas T2DM likely represents the most common form of diabetes that a dental professional would encounter in their practice due to its prevalence, the authors cannot assume that the participants only considered this form of diabetes while responding to the survey. It is important to acknowledge that etiological differences that give rise to pathogenic mechanisms that determine various forms of diabetes also require distinct clinical strategies based on the patient's diabetes type for approaching oral health and medical management and achievement of glycemic control. 
Future studies surrounding dental provider knowledgeability may focus more specifically on a specific form of diabetes to inform establishment of disease-specific ICMs.

Finally, this study focused only on surveying dental providers practicing in the state of Wisconsin and therefore generalizability to other states or nationally remains to be determined. Future studies in other states/regions of the USA could explore reproducibility of the study findings reported herein in other regional settings across the country in order to determine whether barriers or factors contributing to adoption of ICMs are consistently identifiable or vary regionally. Definition of consistently identifiable contributing variables would inform a targeted approach for creating successful ICMs and could accelerate more universal adoption to promote greater achievement of integrated care delivery.

\section{DATA AVAILABILITY STATEMENT}

The raw data supporting the conclusions of this article will be made available by the authors, without undue reservation.

\section{ETHICS STATEMENT}

The studies involving human participants were reviewed and approved by Marshfield Clinic Research Institute's Institutional Review Board, Marshfield Clinic Research Institute. Written informed consent for participation was not required for this study in accordance with the national legislation and the institutional requirements.

\section{AUTHOR CONTRIBUTIONS}

NS contributed to design of the study, acquisition of data, analysis and interpretation of data and was involved in drafting the article and revising it critically for important intellectual content, and the final approval of the version. AP was involved in analysis and interpretation of data, drafting of the manuscript, and final

\section{REFERENCES}

1. Stohr J, Barbaresko J, Neuenschwander M, Schlesinger S. Bidirectional association between periodontal disease and diabetes mellitus: a systematic review and meta-analysis of cohort studies. Scientific Reports. (2021) 11:13686. doi: 10.1038/s41598-021-93062-6

2. Preshaw PM, Alba AL, Herrera D, Jepsen S, Konstantinidis A, Markrilakis K, et al. Periodontitis and diabetes: a two-way relationship. Diabetologia. (2012) 55:21-31. doi: 10.1007/s00125-011-2342-y

3. Chapple ILC, Genco R. working group 2 of the joint EFP/AAP workshop. Diabetes and periodontal diseases: consensus report of the joint EFP/AAP workshop on periodontitis and systemic diseases. J Periodontol. (2013) 84:S106-12. doi: 10.1902/jop.2013.1340011

4. Mealey BL. Periodontal disease and diabetes. a two-way street. J Am Dent Assoc. (2006) 137 Suppl: 26S-31. doi: 10.14219/jada.archive.2006.0404

5. Jeffcoat MK, Jeffcoat RL, Gladowski PA, Bramson JB, Blum JJ. Impact of periodontal therapy on general health. Am J Prev Med. (2014) 47:16674. doi: 10.1016/j.amepre.2014.04.001

6. Ide R, Hoshuyama T, Takahashi K. The effect of periodontal disease on medical and dental costs in a middle-aged japanese population: a longitudinal worksite study. J Periodontol. (2007) 78:2120-6. doi: 10.1902/jop.2007.070193 approval. IG contributed to analysis and data interpretation and was involved in manuscript review and final approval version. P-HC contributed to statistical analysis, data interpretation and was involved in manuscript review, and final approval version. AA contributed to conception and design of the study, analysis and interpretation of the data, reviewing and revising it critically for important intellectual content and final approved version. All authors contributed to the article and approved the submitted version.

\section{FUNDING}

This study was supported by funding from Delta Dental of Wisconsin; Marshfield Clinic Research Institute and partial funding by grant UL1TR000427 from Clinical and Translational Science Award (CTSA) program of the National Center for Advancing Translational Sciences, National Institutes of Health (NIH).

\section{ACKNOWLEDGMENTS}

The authors wish to acknowledge Dixie Schroeder from Center for Oral and Systemic Health at Marshfield Clinic Research Institute for her assistance with coordinating the survey dissemination. The authors further acknowledge assistance from Cathy Schneider from Biomedical Informatics Research Center and Yvonne Cerne from the Center for Oral and Systemic Health for her assistance with survey tool formatting and for preparation of the data sets for analysis. The authors thank Callahan Katrak for assisting with the thematic analysis.

\section{SUPPLEMENTARY MATERIAL}

The Supplementary Material for this article can be found online at: https://www.frontiersin.org/articles/10.3389/fdmed. 2021.674178/full\#supplementary-material

7. Choi SE, Sima C, Pandya A. Impact of treating oral disease on preventing vascular diseases: a model-based cost-effectiveness analysis of periodontal treatment among patients with type 2 diabetes. Diabetes Care. (2020) 43:56371. doi: $10.2337 / \mathrm{dc} 19-1201$

8. Teeuw WJ, Gerdes VEA, Loos BG. Effect of periodontal treatment on glycemic control of diabetic patients: a systematic review and meta-analysis. Diabetes Care. (2010) 33:421-7. doi: 10.2337/dc09-1378

9. Corbella S, Francetti L, Taschieri S, Siena FD, Fabbro MD. Effect of periodontal treatment on glycemic control of patients with diabetes: a systematic review and meta-analysis. J Diabetes Investig. (2013) 4:502-9. doi: 10.1111/jdi.12088

10. Smits KPJ, Listl S, Plachokova AS, Galien OV, Kalmus O. Effect of periodontal treatment on diabetes-related healthcare costs: a retrospective study. BMJ Open Diabetes Res Care. (2020) 8:1666. doi: 10.1136/bmjdrc-2020-001666

11. Northridge ME, Birenz S, Gomes DM, Golembeski CA, Greenblatt AP, Shelley $\mathrm{D}$, et al. Views of dental providers on primary care coordination at chairside: a pilot study. J Dent Hyg JDH. (2016) 90:170-80.

12. Lalla E, Kunzel C, Burkett S, Cheng B, Lamster IB.Identification of unrecognized diabetes and pre-diabetes in a dental setting. J Dent Res. (2011) 90:855-60. doi: 10.1177/0022034511407069

13. Shimpi N, Schroeder D, Kilsdonk J, Chyou PH, Glurich I. Acharya A. Assessment of dental providers' knowledge, behavior and attitude towards 
incorporating chairside screening for medical conditions : a pilot study. (2016) 2:1-7. doi: 10.15744/2454-3276.2.102

14. Evans CA, Kleinman DV. The surgeon general's report on America's oral health: opportunities for the dental profession. J Am Dent Assoc. (2000) 131:1721-8. doi: 10.14219/jada.archive.2000.0118

15. Dye BA, Li X, Thorton-Evans G. Oral Health Disparities As Determined By Selected Healthy People 2020 Oral Health Objectives For The United States, 2009-2010. Hyattsville, MD: CDC/NCHS. (2012).

16. Shimpi N, Schroeder D, Kilsdonk J, Chyou PH, Glurich I, Penniman E, et al. Medical providers' oral health knowledgeability, attitudes, and practice behaviors: an opportunity for interprofessional collaboration. J Evid Based Dent Pract. (2016)16:19-29. doi: 10.1016/j.jebdp.2016.01.002

17. Glurich I, Schwei KM, Lindberg S, Shimpi N, Acharya A. Integrating medical-dental care for diabetic patients: qualitative assessment of provider perspectives. Health Promot Pract. (2017) 19:531-41. doi: 10.1177/1524839917737752

18. Panny A, Krueger K, Acharya A. Achieving the 'True' triple aim in healthcare. In: Acharya A, Powell V, Torres-Urquidy MH, editors. Integration of Medical and Dental Care and Patient Data. Switzerland AG: Springer Nature Springer International Publishing. p. 11-32. doi: 10.1007/978-3-319-98298-4_2

19. Poudel P, Griffiths R, Wong VW, Arora A, George A. Knowledge and practices of diabetes care providers in oral health care and their potential role in oral health promotion: a scoping review. Diabetes Res Clin Pract. (2017) 130:266-77. doi: 10.1016/j.diabres.2017.06.004

20. American Diabetes Association. The Burden of Diabetes By State. (2016). Available online at http://main.diabetes.org/dorg/PDFs/Advocacy/burdenof-diabetes/all-states.pdf (accessed Oct 10, 2021).

21. Wisconsin Department of Health Services. Chronic Disease Prevention Program. Wisconsin Department of Health Services. (2018). Available online at https://www.dhs.wisconsin.gov/disease/burden-chronic.htm (accessed Oct 10, 2021).

22. American Diabetes Association. 2017 Wisconsin Diabetes Clinical Care Recommendations At-A-Glance. (2017). Available online at https://www.dhs. wisconsin.gov/publications/p49356a.pdf (accessed Oct 10, 2021).

23. Harris PA, Taylor R, Thielke R, Payne J, Gonzalez N, Conde JG. Research electronic data capture (REDCap)-a metadata-driven methodology and workflow process for providing translational research informatics support. $J$ Biomed Inform. (2009) 42:377-81. doi: 10.1016/j.jbi.2008.08.010

24. Paquette DW, Bell KP, Phillips C, Offenbacher S, Wilder RS. Dentists' knowledge and opinions of oral-systemic disease relationships: relevance to patient care and education. $J$ Dent Educ. 24: 79:626-35 doi: 10.1002/j.0022-0337.2015.79.6.tb05934.x

25. Esmeili T, Ellison J, Walsh MM. Dentists' attitudes and practices related to diabetes in the dental setting. J Public Health Dent. (2010) 70:10814. doi: 10.1111/j.1752-7325.2009.00150.x

26. Boyd LD, Hartman-Cunningham ML. Survey of diabetes knowledge and practices of dental hygienists. J Dent Hyg JDH. (2008) 82:43.

27. Greenberg BL, Glick M, Frantsve-Hawley J, Kantor ML. Dentists' attitudes toward chairside screening for medical conditions. J Am Dent Assoc. (2010) 141:52-62. doi: 10.14219/jada.archive.2010.0021

28. Greenberg B, Kantor M, Bednarsh H. American dental hygienists' attitudes towards chairside medical screening in a dental setting. Int J Dent Hyg. (2017) 15:e61-8. doi: 10.1111/idh.12217

29. Friman G, Hultin M, Nilsson GH, Wardh I. Medical screening in dental settings: a qualitative study of the views of authorities and organizations health services research. BMC Res Notes. (2015) 8:580. doi: 10.1186/s13104-015-1543-8

30. Shimpi N, Glurich I, Panny A, Acharya A. Knowledgeability, attitude, and practice behaviors of primary care providers toward managing patients' oral health care in medical practice: Wisconsin statewide survey. J Am Dent Assoc. (2019) 150:863-72. doi: 10.1016/j.adaj.2019.05.020
31. Kunzel C, Lalla E, Lamster I. Dentists' management of the diabetic patient: contrasting generalists and specialists. Am J Public Health. (2007) 97:72530. doi: 10.2105/AJPH.2006.086496

32. Hegde H, Shimpi N, Panny A, Glurich I, Christie P, Acharya A. Development of non-invasive diabetes risk prediction models as decision support tools designed for application in the dental clinical environment. Informatics Med Unlocked. (2019). doi: 10.1016/j.imu.2019.100254

33. Glurich I, Bartkowiak B, Berg RL, Acharya A. Screening for dysglycaemia in dental primary care practice settings: systematic review of the evidence. Int Dent J. (2018) 68:369-77. doi: 10.1111/idj.12405

34. Acharya A, Cheng B, Koralkar R, Olson B, Lamster IB, Kunzel C, et al. Screening for diabetes risk using integrated dental and medical electronic health record data. JDR Clin Transl Res. (2018) 3:18894. doi: 10.1177/2380084418759496

35. Lalla E, Cheng B, Kunzel C, Burkett S, Lamster IB. Dental findings and identification of undiagnosed hyperglycemia. J Dent Res. (2013) 92:88892. doi: 10.1177/0022034513502791

36. Borrell LN, Kunzel C, Lamster I, Lalla E. Diabetes in the dental office: using NHANES III to estimate the probability of undiagnosed disease. J Periodontal Res. (2007) 42:559-65. doi: 10.1111/j.1600-0765.2007.00 983.x

37. Association AD. Type 2 Diabetes. (2018). Available online at: http://www. diabetes.org/diabetes-basics/type-2/ (accessed July 1,2018).

38. Fritz P, Ward W, Longo A. The New Global Classification System for Periodontal and Peri-Implant Diseases: An Executive Summary for the Busy Dental Professional. Oral Health. (2018). Available online at: https://www. oralhealthgroup.com/features/the-new-global-classification-system-forperiodontal-and-peri-implant-diseases-an-executive-summary-for-thebusy-dental-professional (accessed Sep 12, 2021).

39. Park SE, Donoff RB, Saldana F. The impact of integrating oral health education into a medical curriculum. Med Princ Pract. (2017) 26:615. doi: 10.1159/000452275

40. Hein C, Schönwetter DJ, Iacopino AM. Inclusion of oral-systemic health in predoctoral/undergraduate curricula of pharmacy, nursing, and medical schools around the world: a preliminary study. J Dent Educ. (2011) 75:118799. doi: 10.1002/j.0022-0337.2011.75.9.tb05162.x

41. CDC Announces Medical-Dental Integration Partnership. (2020). Available online at: https://www.cdc.gov/oralhealth/about/md-integration.html (accessed February 18, 2021).

Author Disclaimer: The content of this paper is solely the responsibility of the authors and does not necessarily represent the official views of the NIH.

Conflict of Interest: The authors declare that the research was conducted in the absence of any commercial or financial relationships that could be construed as a potential conflict of interest.

Publisher's Note: All claims expressed in this article are solely those of the authors and do not necessarily represent those of their affiliated organizations, or those of the publisher, the editors and the reviewers. Any product that may be evaluated in this article, or claim that may be made by its manufacturer, is not guaranteed or endorsed by the publisher.

Copyright (c) 2021 Shimpi, Panny, Glurich, Chyou and Acharya. This is an openaccess article distributed under the terms of the Creative Commons Attribution License (CC BY). The use, distribution or reproduction in other forums is permitted, provided the original author(s) and the copyright owner(s) are credited and that the original publication in this journal is cited, in accordance with accepted academic practice. No use, distribution or reproduction is permitted which does not comply with these terms. 